\title{
Controlled trial comparing olsalazine and sulphasalazine for the maintenance treatment of ulcerative colitis
}

\author{
A IRELAND, C H MASON, AND D P JEWELL \\ From the Gastroenterology Unit, Radcliffe Infirmary, Oxford
}

SUMMARY One hundred and sixty four patients with ulcerative colitis in remission were entered into a double blind, double dummy trial comparing olsalazine $500 \mathrm{mg}$ bd and sulphasalazine $1 \mathrm{~g}$ bd. Clinical examination, sigmoidoscopy and rectal biopsy were performed at 0 , three, and six months. Sixteen of $82(19 \cdot 5 \%)$ patients relapsed on olsalazine and $10 / 82(12 \cdot 2 \%)$ relapsed on sulphasalazine. The difference was not statistically significant $(p=0 \cdot 1632)$. Adverse events were minor and were similar in both groups. No haematological or biochemical abnormalities were detected. Thus, olsalazine is as effective as sulphasalazine for preventing a relapse of ulcerative colitis.

Sulphasalazine (SASP) has been the mainstay of maintenance therapy for ulcerative colitis (UC) since its discovery in $1940{ }^{1-3}$ Increasing awareness of the side effects of the sulphapyridine (SP) moiety, ${ }^{4}$ coupled with the discovery that 5-ASA is the active ingredient for $\mathrm{UC},{ }^{5}$ has resulted in extensive investigation into alternative ways of delivering 5-ASA to the colon. Olsalazine (Dipentum ${ }^{\circledR}$ ) is a drug in which the SP molecule is replaced by another molecule of 5-ASA, the drug thereby releasing two molecules of 5-ASA upon azo reduction in the colon." Olsalazine is of proven value in patients intolerant of SASP,${ }^{7 x}$ and is also effective when given orally to patients with a mild relapse of UC. ${ }^{9}$ A recent Swedish study has shown it to be superior to placebo in maintaining UC in remission over a six month period."'

The aim of this study was to compare olsalazine with sulphasalazine in patients with UC in remission, over a six month period.

\section{Methods \\ PATIENTS \\ One hundred and sixty four patients attending for outpatient follow up were recruited over an 18 month period. The patients were men or women, and aged between 18 and 75 years on entry to the study. \\ Address for correspondence: Dr D P Jewell, Gastroenterology Unit, Radeliffe Infirmary. Oxford OX2 $6 \mathrm{HE}$ \\ Received for publication 7 December 1987}

Patients were excluded from the trial if they had active disease, hepatic or renal dysfunction, allergies to sulphonamides or salicylates and, if young women, were not taking adequate contraceptive precautions. All had UC in remission, and were taking regular sulphasalazine in an average dose of $1 \mathrm{~g}$ bd. Table 1 shows the background characteristics of the patient population. Remission was defined as an absence of colitis symptoms together with an absence of inflammation on sigmoidoscopy. The patients were required not to have had a relapse of their ulcerative colitis during the preceding six months, or to have received corticosteroids, azathioprine, or metronidazole during that period.

The duration of the trial was six months. On entry, and at three and six months, a history was taken and clinical examination, sigmoidoscopy, and rectal biopsy were carried out. Sigmoidoscopy appearances

Table 1 Background data

\begin{tabular}{lll}
\hline & Sulphasalazine & Olsalazine \\
\hline $\mathrm{n} \quad$ & 82 & 82 \\
$\mathrm{Age}$ (mean) & 47 & 49 \\
$\mathrm{Sex}$ & $17-75$ & $18-75$ \\
& $43 \mathrm{female}$ & $34 \mathrm{female}$ \\
Duration of disease (mean) & 39 male & 48 male \\
SASP on entry & $10 \cdot 5$ years & $13 \cdot 1$ years \\
Extent of disease & 81 proctitis & 81 \\
& 37 proctitis \\
& 25 left sided & 26 left sided \\
& 20 total & 17 total \\
\hline
\end{tabular}


were graded $0-3$ according to the criteria of Truelove and Witts. " Rectal biopsies were graded according to the criteria of Truelove and Richards. ${ }^{2}$ Histology was only analysed if taken within two weeks of the relapse date. Blood was taken for routine haematology and biochemistry at each visit. Verbal consent was obtained from all the patients, and the study had approval of the hospital ethical committee. Patients were withdrawn from the study if they relapsed or if any side effects occurred which necessitated stopping therapy. A relapse was defined as increased stool frequency with or without blood or mucus and with evidence of inflammation on sigmoidoscopy.

The study used a double blind, double dummy design with the SASP tablets containing $0.5 \mathrm{~g}$ SASP and the olsalazine capsules containing $0.25 \mathrm{~g}$ olsalazine. Dosage was two capsules and two tablets twice daily, corresponding to either $2 \mathrm{~g}$ SASP daily or $1 \mathrm{~g}$ olsalazine daily. Randomisation was in blocks of 10 , and the drugs were dispensed by the hospital pharmacy.

The large number of patients entered in this trial was necessary in order to minimise the risk of a Type 2 error leading to an erroneous interpretation of the results. Thus, 164 patients were entered to test the difference between the two treatments at the 0.05 level with $80 \%$ power, setting $\alpha$ at 0.05 and $\beta$ at 0.2 , assuming a uniform dropout rate of $10 \%$, and a $20 \%$ difference in relapse rate between treatment groups. Comparative statistical testing for differences between treatment groups was performed using $\chi^{2}$ analysis or Fisher's exact test for discrete variables, and $t$-test for continuous variables. The life-table method to compare the cumulative relapse rates was used, using the generalised Wilcoxon's test.

\section{Results}

Sixteen of $82(19.5 \%)$ patients relapsed on olsalazine over the six month period, and $10 / 82(12.2 \%)$ relapsed on SASP. The difference in relapse rates between the two groups was $7 \cdot 3 \%$, the $95 \%$ confidence limits being $-3 \cdot 8 \%$ and $18 \cdot 4 \%$ respectively. This difference is not statistically significant $(p=0 \cdot 1632)$. The relapse rate was also analysed using life table analysis. The Figure shows that the cumulative relapse rate was similar in both groups and that the time between entry into the study and relapse was also similar in each group. The difference was not statistically significant $(p=0 \cdot 1314)$. Five patients were lost to follow up (three olsalazine, two SASP). Forty one patients reported an adverse event during the course of the trial, 21 in the olsalazine group and 20 in the SASP group. None were serious, and many were felt to be unrelated to the drug therapy. Twenty five of 41 were withdrawn from the

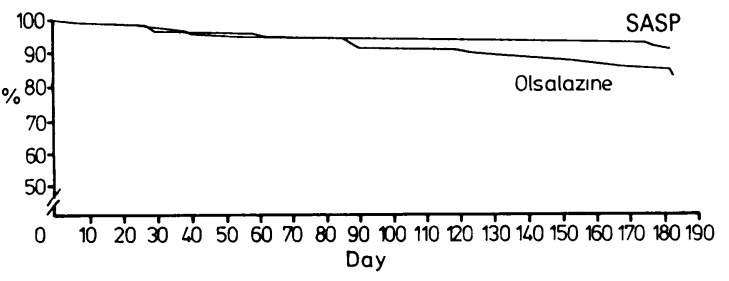

Figure Life table.

trial, 16 in the olsalazine group and nine in the SASP group, the reasons being shown in Table 2 . The difference in numbers is not statistically significant. In those patients complaining of diarrhoea there was no consistent relationship with extent of disease (Table 3), and the frequency of diarrhoea in the two groups was not significantly different $(p=0 \cdot 1264)$.

On entry into the trial, no inflammation was present in the initial rectal biopsy specimens of $61 / 82$ patients in the olsalazine group and of 62/82 in the SASP group. When clinical relapse occurred, there was evidence of a histological relapse in the vast majority of patients. Four patients in the olsalazine group, however, and three patients in the SASP group had a clinical and sigmoidoscopic relapse with no subsequent evidence of histological inflammation. There was no suggestion that a relapse on olsalazine was any more severe than on sulphasalazine.

All patients were in clinical and sigmoidoscopic remission on entry to the study, but 32 patients had histological evidence of active disease ( 24 mild, six moderate, two severe). There was a trend for these patients to have a higher relapse rate, but this failed to reach statistical significance. In particular, none of the patients with moderate or severe changes relapsed.

Table 2 Reasons for withdrawal

\begin{tabular}{lrlr}
\hline Olsalazine & & Sulphasalazine \\
\hline Diarrhoca & 10 & Diarrhoca & 3 \\
Abdominal pain & 2 & Indigestion & 2 \\
Indigestion & 2 & Depression & 1 \\
Arthralgia & 1 & Rash & 1 \\
Itching & 1 & Concurrent illness & 1 \\
& & & 9 \\
\hline
\end{tabular}

Table 3 Number of patients with diarrhoea on treatment

\begin{tabular}{llc}
\hline & $\begin{array}{l}\text { Olsalazine } \\
n=82\end{array}$ & $\begin{array}{l}S A S P \\
n=82\end{array}$ \\
\hline Proctitis & 6 & 2 \\
Left sided & 2 & 0 \\
Total & 2 & 1 \\
\hline
\end{tabular}


There were no clinically significant alterations in any of the haematological or biochemical parameters.

\section{Discussion}

Olsalazine is one of many 5-ASA containing compounds developed since the discovery that 5-ASA was the active ingredient of sulphasalazine for the treatment of UC. Sulphasalazine is widely used and tolerated, but $10-15 \%$ of patients cannot take the drug because of side effects. ${ }^{+}$The majority of these side effects are thought to be caused by the SP moiety, which acts purely as a carrier molecule. Side effects are particularly troublesome in slow acetylators, who have high circulating SP concentrations. ${ }^{13}$ Olsalazine is an azo-compound which requires the parent compound to be split by colonic bacteria, thus releasing two molecules of 5-ASA. High concentrations of 5-ASA are found in faecal water,${ }^{1+}$ where the drug is presumed to act by a local mechanism. Olsalazine is a useful agent in mild to moderately active left sided UC, ${ }^{,}$and is superior to placebo as a maintenance agent. "' The results of our study confirm its usefulness as a maintenance drug, and there is no difference between it and SASP. It is especially useful in those patients who are intolerant of SASP. ${ }^{8}$ The incidence of adverse effects is no different from that with SASP, and although a greater number of cases of diarrhoea were reported, this difference was not statistically significant. Diarrhoea can sometimes be a problem in SASP treated patients, ${ }^{+}$but in this study the population was preselected to be tolerant of SASP. Diarrhoea with olsalazine has been reported with an incidence of approximately $10 \%$ in other studies, ${ }^{78}$ and in the Swedish study ${ }^{7}$ it seemed to be related to the extent of disease, being more common in those with total colitis. In our study, there is no consistent relationship between extent of disease and incidence of diarrhoea. The diarrhoea appears to be a dose related effect, and is thought to be caused by an action of the parent molecule on the small intestine. It has been shown to increase small intestinal fluid output in a group of ileostomy patients ${ }^{15}$ and in isolated rat jejunum, it inhibits the transport of glucose and water. ${ }^{16}$ The increased fluid load would normally be accommodated by the colon but, in a diseased state, this mechanism may be less efficient. In many instances, the loose stools are transient, and can return to normal either by reducing the dose or occasionally by continuing on the drug (personal observation).

In summary, we have shown that olsalazine $500 \mathrm{mg}$ bd is as effective as sulphasalazine $1 \mathrm{~g}$ bd in maintaining UC in remission over a six month period. It is free of serious side effects, and has the additional advantage of being useful in those patients who are intolerant of SASP.

We are grateful to Dr Sven Ljungberg of Pharmacia $\mathrm{AB}$, Sweden, and to Dr Sidney Truelove for helpful advice. Mrs Zena Jennings provided invaluable secretarial assistance.

\section{References}

1 Svartz N. Salazopyrin, a new sulfanilamide preparation. Acta Med Scand 1942; 110: 577-98.

2 Misiewicz JJ, Lennard-Jones JE, Connell AM, Baron $\mathrm{JH}$, Avery Jones F. Controlled trial of sulphasalazine in maintenance therapy for ulcerative colitis. Lancet 1965 ; i: $185-8$.

3 Dissanayake AS, Truelove SC. A controlled therapeutic trial of long-term maintenance treatment of ulcerative colitis with sulphasalazine. Gut 1973; 14: 923-6.

4 Taffet SL, Das KM. Sulphasalazine - adverse effects and desensitization. Dig Dis Sci 1983; 28: 833-42.

5 Azad Khan AK, Piris J, Truelove SC. An experiment to determine the active therapeutic moiety of sulphasalazine. Lancet 1977; ii: 892-5.

6 Willoughby $\mathrm{CP}$, Aronson JK, Agback H, Bodin NO, Truelove SC. Distribution and metabolism in healthy volunteers of disodium azodisalicylate, a potential therapeutic agent for ulcerative colitis. Gut 1982; 23: 1081-7.

7 Sandberg-Gertzen H, Jarnerot G. A tolerance study of azodisal sodium (ADS), Dipentum ${ }^{\mathrm{TM}}$, in sulphasalazine intolerant patients with ulcerative colitis. Gastroenterology 1985; 88: 1568 .

8 Ireland A, Jewell DP. Olsalazine in patients intolerant of sulphasalazine. Gastroenterology 1986; 90: 1471.

9 Selby WS, Barr GD, Ireland A, Mason CH, Jewell DP. Olsalazine in active ulcerative colitis. Br Med J 1985; 291: 1373-5.

10 Sandberg-Gertzen H, Jarnerot G, Kraaz W. Azodisal sodium in the treatment of ulcerative colitis. Gastroenterology 1986; 90: 1024-30.

11 Truelove SC, Witts LJ. Cortisone in ulcerative colitis. Br Med J 1955; ii: 1041-8.

12 Truelove SC, Richards WCD. Biopsy studies in ulcerative colitis. $B r$ Med J 1956; i: 1315-8.

13 Das KM, Eastwood MA. Acetylation polymorphism of sulphapyridine in patients with ulcerative and Crohn's disease. Clin Pharmacol Ther 1975; 18: 514-20.

14 Lauritsen K, Hansen J, Ryde M, Rask-Madsen J. Colonic azodisalicylate metabolism determined by in vivo dialysis in healthy volunteers and patients with ulcerative colitis. Gastroenterology 1984; 86: 1496-5()).

15 Sandberg-Gertzen $H$, Jarnerot $G$, Bukhave $K$, Lauritsen K, Rask-Madsen J. Effect of azodisal sodium and sulphasalazine on ileostomy output of fluid, $\mathrm{PGE}_{2}$ and $\mathrm{PGF}_{2}$ in subjects with a permanent ileostomy. Gut 1987; 27: 1306-11.

16 Mohsen AQM, Mulvey D, Priddle JD, Parsons DS, Jewell DP. The effects of olsalazine in the jejunum of the rat. Gut 1987; 28: 346-52. 